\title{
Breast pain in lactating mothers
}

\author{
Sophie SF Leung *
}

\section{A B S T R A C T}

Introduction: The number of new mothers who breastfeed has increased dramatically over the last three decades. There is a concern that the present related medical service may be inadequate. Breast pain is the most common complaint among lactating mothers who seek medical help. This study aimed to investigate this problem.

Methods: Medical records of women who presented with breast pain to a private clinic run by a doctor who was trained as an International Lactation Consultant were reviewed over a period of 6 months in 2015. Most patients were selfreferred after chatting online. Assessment included characteristics and duration of pain, treatment prior to consultation, feeding practices, mother's diet, and breast examination. Any site of blockage was identified and relieved. Those with persistent pain were given antibiotics. When there were signs of abscess or abscess that could not be drained, they were referred to a breast surgeon.

Results: A total of 69 patients were seen of whom 45 had been breastfeeding for more than 1 month. Pain was experienced for longer than 7 days in 22 women.

This article was published on 17 Jun 2016 at www.hkmj.org. Antifungal or antibacterial treatment had been

unsuccessful in 31 women prior to consultation. The ${ }^{*}$ Corresponding author: dr.leung@ssfl.com.hk

diagnoses were engorgement in five women, blocked duct in 35 , mastitis in 13 , breast abscess in six, poor positioning and latch in seven, nipple cracks in two, and skin infection in one. Oral antibiotics were prescribed to 21 patients and local antifungal treatment was given to one patient only.

Conclusion: Blocked duct was the most common cause of breast pain in lactating mothers. Without prompt relief it is possible that it will progress to mastitis/breast abscess or the mother may discontinue breastfeeding. This may be a suitable time for Hong Kong to set up one or more public fulltime breastfeeding clinics to provide a better service to lactating mothers and to facilitate professional training and research.

\section{Hong Kong Med J 2016;22:341-6 \\ DOI: 10.12809/hkmj154762}

SSF Leung *, FHKCPaed, FHKAM (Paediatrics)

Department of Paediatrics, The Chinese University of Hong Kong, Shatin, Hong Kong (c/o: Room 1502, 15/F, Hong Kong Pacific Centre, 28 Hankow Road, Tsimshatsui, Hong Kong)

New knowledge added by this stud

- Most breast pain in lactating mothers is not necessarily due to bacterial or fungal infection but due to duct blockage that can be relieved promptly by gentle breast massage and milk expression.

- Local mothers had a specific dietary practice to encourage milk production that could sometimes be harmful.

Implications for clinical practice or policy

- To cope with the increased prevalence of breastfeeding, relevant clinical services should be established, including one or more full-time breastfeeding clinics in the public sector that mothers can attend without the need for medical referral. This will also help in research since local practices and clinical problems may differ to those described in the literature.

\section{Introduction}

Hong Kong has experienced a tremendous change in lifestyle and the consequent clinical problems pose a challenge to the medical profession. A good example of this is infant feeding. Almost half a century ago, the prevalence of breastfeeding in Hong Kong was at its lowest rate of $5 \%$ in 1978 after a dramatic fall from $44 \%$ in $1967 .{ }^{1}$ Following the joint efforts of doctors, nurses and mothers, the prevalence of the ever breastfeeding rate in Hong Kong has rapidly climbed from $20 \%$ in 1992 to $60 \%$ in 2002 and $86 \%$ in 2014. ${ }^{2}$ The efforts of both the UNICEF BabyFriendly Hospital Initiative and the Department of
Health should be applauded.

Breast milk is the best for babies. Mothers should be encouraged to breastfeed fully for 6 months, followed by introduction of solid foods and continuation of breastfeeding for 2 years or more. Recent data have shown that only $27 \%$ of mothers can sustain breastfeeding for 4 to 6 months. ${ }^{2}$ There are areas where we, as medical professionals, can provide support. For historical reasons, however, not many local doctors and nurses have been trained to manage the clinical problems encountered by breastfeeding mothers. One such problem is breast pain.

Breast pain, which may lead to cessation of 


\section{哺乳期婦女的乳房疼痛}

\section{梁淑芳}

引言：過去30年, 母乳餵哺率有顯著上升的趨勢, 目前的醫療設施可 能未足以應付有關需要。母乳餵哺期間最常見的問題是乳房疼痛。本 研究分析其病因。

方法：回顧2015年6個月內因乳房疼痛向一所私營診所求診的病人紀 錄, 診所醫生曾受訓為國際認証泌乳顧問。大多數求診病人因在網上 聊天而自行到診所求診。臨床評估包括疼痛特點和疼痛期、曾接受的 治療方法、餵哺習慣、乳母飲食及乳房檢查, 亦為病人檢查乳腺阻塞 的位置並進行疏通, 並處方抗生素予仍有疼痛的患者。已出現膿腫而 未能排膿者, 則會轉介至乳腺外科醫生。

結果：研究期間共有69名病者, 其中45例哺乳超過一個月, 22例的痛 楚超過 7 天。 31 例曾接受抗真菌或抗細菌藥物但未獲舒緩。診斷結果 為脹痛5例、乳管堵塞 35 例、乳腺炎 13 例、乳腺膿腫6例、姿勢與含接 不良 7 例、乳頭損裂 2 例和皮膚感染 1 例。 21 例須處方抗生素, 只有 1 例 需抗真菌藥物。

結論：乳腺阻塞是乳房疼痛的主要原因, 若不及早治療可導致乳腺 炎、乳腺膿腫, 甚至須停止母乳餵哺。也許現在是時候設立一個或多 個公共母乳餵哺門診, 既能為哺乳期婦女提供服務之餘, 亦有助促進 相關專業訓練和研究。 breastfeeding, is the most common complaint of lactating mothers seen in a private general paediatric clinic run by a doctor (author) trained in 2000 as an International Lactation Consultant. This study aimed to analyse the reasons for breast pain and how it can be relieved.

\section{Methods}

Clinical records of lactating mothers who presented with breast pain over a 6-month period (January to June 2015) were retrieved. Patients were self-referred after chatting online with other breastfeeding mothers. During consultation, patients were asked about the history of pain, prior treatment, breastfeeding practices, and their own diet. Breast examination was then performed, including the nipple and areola, to identify any redness or tenderness. In particular, any blockage was identified.

If redness or tenderness was generalised in either or both breasts, it was diagnosed as engorgement (Fig a). If it was confined to a segment, this implied only a lobule was involved. If gentle massage and milk expression provided relief, a blocked duct was diagnosed (Fig b). The ability to express pus (Fig c) or an area of fluctuation or skin thinning (Fig d) was indicative of breast abscess. Mastitis was diagnosed in the presence of fever and tenderness/mass that could not be relieved but had not progressed to an abscess. ${ }^{3}$ Nipples were examined for cracks (Fig e). Feeding position and latch were checked when appropriate and corrected accordingly. When there was a white spot in the nipple, it was cleared by simple expression or by using a needle to open up the blockage. If there was a shinny reddish colour of the nipple and areola together with burning, stinging, and itchiness then fungal infection was diagnosed. In such case, the baby's mouth was also examined for the presence of oral thrush.

\section{Results}

A total of 69 patients were seen of whom 45 had been breastfeeding for more than 1 month. All except six were in their 30s. The age of the baby was less than 1 month in 24 (35\%) women, 1 to 6 months in 27 (39\%), and over 6 months in 18 (26\%). Only 13 (19\%) used complementary infant milk formula.

Breast pain was present for less than 3 days in 35 (51\%) women but for longer in the remaining 34 (49\%). Pain duration exceeded 7 days in 22 (32\%); 15 (22\%) of whom had intermittent pain for 14 to 30 days. In 31 (45\%) patients, earlier treatment had been received from various sources including Maternal and Child Health Centres (MCHCs), family doctors, general practitioners, obstetricians, doctors at an accident and emergency department, surgeons in a breast surgery clinic, or lactation consultants. Antifungal or antibacterial medication, either local or systemic, was prescribed.

Apart from breast pain, there were other

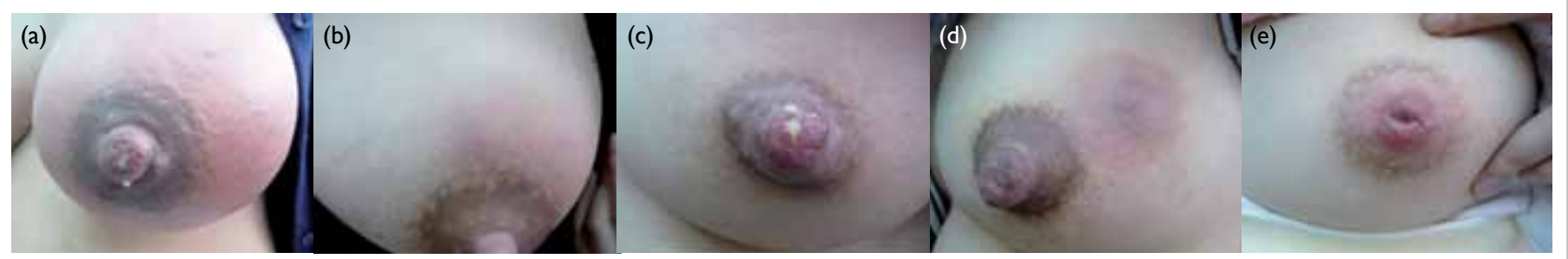

FIG. (a) General redness of breast due to engorgement. (b) Local area of redness in blocked duct or mastitis. (c) Pus expressed from breast abscess. (d) Bluish area with sign of fluctuation. (e) Cracks in nipple (highlight with mercurochrome solution) 
additional complaints: nipple pain in eight (12\%) women, sharp needle pain after feeding in eight (12\%), white spot at nipple in $15(22 \%)$, and fever in $14(20 \%)$. All had decreased milk production by the affected breast despite frequent feeding or pumping.

The following diagnoses were made: nipple cracks $(n=2)$, poor positioning and latch $(n=7)$, engorgement $(n=5)$, blocked duct $(n=35)$, mastitis $(n=13)$, breast abscess $(n=6)$, and skin infection $(\mathrm{n}=1)$. One had all pus drained via the milk duct. Another had pus formed in the sebaceous gland at the areola and was fully drained. The remaining four were referred to a surgeon for further management. Oral antibiotics were prescribed to $21(30 \%)$ women. Fungal infection was suspected in only one woman. Clinical details of four patients chosen for illustration are shown in the Table.

\section{Discussion}

Subjects in this study represent mothers who were very dedicated to breastfeeding. Most had been breastfeeding for more than 1 month and had not given up, despite experiencing pain for quite a number of days.

\section{Blocked duct/mastitis}

Blocked duct was the most common cause of breast pain in this study group. Delay in diagnosing and treating a blocked duct can lead to a more serious condition of mastitis and breast abscess.

Engorgement, blocked duct, mastitis, and breast abscess reflect progression from a common original problem of inadequate drainage that can be due to poor positioning and latching, inadequate emptying, or overproduction. ${ }^{3}$ Obtaining a good history, performing a thorough breast examination, and milk expression can help to make the diagnosis.

Engorgement usually involves the whole breast whereas a blocked duct involves a lobule. In the latter, redness and tenderness are apparent and examination of the areola may reveal a tender swelling representing a blockage of the duct near the opening. Gentle massage and milk expression will relieve the pain and tenderness. A simple blocked duct can be relieved immediately. Nonetheless, when the swelling can only be partially relieved, it may represent tissue inflammation indicative of mastitis. Mothers were encouraged to feed more often on the affected breast. If this failed after one or two feeds, antibiotics were prescribed to prevent progression to breast abscess.

Milk is a very good medium for bacterial culture. Stasis of milk for too long may lead to infection (mastitis) and pus formation (abscess). The common guideline is to relieve a blocked duct as soon as possible, especially in the presence of fever. Once fever has persisted for longer than 24 hours, antibiotics are required. In one woman in this study, however, breast abscess was evident within the first few hours of fever and in another woman without fever, thus fever should be considered a non-specific sign. Clinical assessment was the most important. The ratio of breast abscess to mastitis was higher in this series (46.2\%) compared with that reported in the literature $(11.1 \%){ }^{3}$ This may have been due to a difference in sampling methods or different diagnostic criteria for mastitis. The difference between a blocked duct and mastitis can be very subtle. Presence of redness and tenderness in the breast with little effort to clear the blockage may be classified as mastitis. What is of more concern is the possible delay in management that allows untreated mastitis to progress to breast abscess. An abscess can be drained through the duct manually, but needle aspiration under ultrasound guidance or incision may be required in some cases. If there is an incision, the wound must be left open for continuous drainage and the mother may be forced to stop breastfeeding.

Since most of these infections are due to Staphylococcus aureus, Streptococcus, or Escherichia coli, antibiotics chosen should be amoxicillin with clavulanate, cloxacillin, or cefuroxime; all of which are compatible with continuation of breastfeeding. ${ }^{3}$

\section{Nipple pain}

Nipple pain may indicate a blocked duct because the duct beneath the areola is swollen. There should be some tenderness although not as much as that of the affected breast lobule. After relief of the blockage, nipple pain will resolve.

A white spot at the nipple may also indicate a blocked duct. Blockage of a lobule and then stasis of milk at the opening of the duct can lead to further blockage by milk that has a high fat or high calcium content. This spot will be white in colour, sometimes referred to as a bleb. It can be removed by milk expression, needle or local application of vegetable oil. This should not be confused with thrush.

Concern has already been raised about the general overdiagnosis of fungal infection as a cause of breast pain, nipple pain, or white spot. ${ }^{4}$ Patients treated for a presumed 'yeast infection' might have shown improvement in symptoms as a result of the anti-inflammatory effect of the antifungal drugs or because the blocked duct resolved on its own. Fungal infection of the breast and nipple may be considered if a blocked duct has been excluded and is often associated with other risk factors. Examples are consuming a diet with high sugar content that promotes growth of fungus, mother having received antibiotics, a maternal history of vaginal candidiasis, or baby's oral mucosa with thrush. ${ }^{4}$ All these risk factors were not found in any of the mothers in this study. Excruciating pain after a feed is a non-specific sign. It is more likely to be due to a blocked duct or inadequate emptying of the breast, as shown in 
TABLE. Clinical details of four patients

\begin{tabular}{|c|c|c|c|c|c|}
\hline $\begin{array}{l}\text { Patient } \\
\text { No. }\end{array}$ & $\begin{array}{c}\text { Age } \\
\text { (years) }\end{array}$ & Baby & $\begin{array}{l}\text { Breast- } \\
\text { feeding }\end{array}$ & Chief complaint & History/prior treatment \\
\hline 1 & 36 & 7 Weeks & Full & $\begin{array}{l}\text { Needle-like breast pain for } 2 \text { weeks in } \\
\text { spite of treatment }\end{array}$ & $\begin{array}{l}\text { Antibiotics was prescribed by doctor in a private hospital } \\
\text { but was not taken by mother. She went for a second } \\
\text { opinion from a lactation consultant. Milk expression } \\
\text { was done with temporary relief and she was told to } \\
\text { apply antifungal cream for } 2 \text { weeks. There was no } \\
\text { improvement even after } 8 \text { days }\end{array}$ \\
\hline 2 & 33 & 1.5 Months & Full & $\begin{array}{l}\text { Left breast pain, unrelieved after } 2 \\
\text { weeks of local antifungal treatment } \\
\text { given by } \mathrm{MCHC}\end{array}$ & $\begin{array}{l}\text { Mother fed baby every } 2 \text { to } 3 \text { hours on one breast and at } \\
\text { the same time pump the other, hoping to save more milk } \\
\text { for the future. Sometimes she went out and did not feed } \\
\text { or pump at the usual time }\end{array}$ \\
\hline 3 & 26 & 4 Months & $\begin{array}{l}\text { Full (through } \\
\text { pumped milk) }\end{array}$ & Breast pain for 2 weeks & $\begin{array}{l}\text { Seen by a private obstetrician. Given a course of } \\
\text { ampicillin with cloxacillin, metronidazole, and etoricoxib, } \\
\text { resulting in no improvement }\end{array}$ \\
\hline 4 & 30 & 2 Months & Full & Breast pain for 11 days & $\begin{array}{l}\text { Received a 7-day course of clarithromycin from } \mathrm{MCHC} \\
\text { with no improvement }\end{array}$ \\
\hline
\end{tabular}

Abbreviation: $\mathrm{MCHC}=$ Maternal and Child Health Centre

this study. These patients had failed to improve after being given local or systemic antifungal treatment in their previous consultations prior to presentation to this clinic. Pain was relieved only after the blocked duct was cleared.

\section{Diet of lactating mothers}

There was a general misunderstanding among the lactating mothers that eating more animal foods could improve milk supply. Previous studies have shown that the protein intake of local lactating mothers is much higher than that of those in other countries. At 3 months postpartum, Hong Kong mothers had a protein intake of $98 \mathrm{~g} /$ day $^{5}$ compared to $81 \mathrm{~g} /$ day in the $\mathrm{UK}^{6}$ and $80 \mathrm{~g} /$ day in Japan. ${ }^{7}$ In the first month after delivery (known locally as the confinement period), the protein intake was even higher $(133 \mathrm{~g} / \text { day })^{5}$ than at 3 months. During this month, local mothers usually consume a special diet consisting of much more pork, fish, chicken, egg, and milk.

The practice of eating a special diet with additional animal foods during confinement may be unique to Hong Kong Chinese population and is likely a long Chinese tradition. The original rationale was to replenish the blood loss of childbirth and may have been necessary at a time when the general population had barely enough food. Prior to the 1960s, our ancestors usually ate a plant-based diet, with pork available only in the Chinese New Year or during some festivals. There was very little over- nutrition. Time has changed. The diet of adults today is generally high in animal protein ${ }^{8}$ and fat. Further increase will lead to new clinical problems, not just weight gain in mothers but also increased risk of blockage and inflammation in breastfeeding mothers. A diet that contains much more meat has been shown to be associated with higher inflammatory index scores ${ }^{9}$ and one of these is Creactive protein. ${ }^{10}$

The quantity and quality of fat in breast milk can be affected by the fat in the maternal diet. Lactating mothers in Chongqing (a major city in Southwest China) consumed a diet wherein fat came from lard. Total fat in the breast milk was higher in Chongqing: $38 \mathrm{~g} / \mathrm{L}$ compared with $32 \mathrm{~g} / \mathrm{L}$ in Hong Kong. ${ }^{11}$ Chongqing mothers did not appear to have problems of blocked ducts or mastitis. Thus, a high-fat diet per se may not cause mastitis, it is the quality of fat that matters. Mothers who consume a diet high in saturated fat may be more prone to duct blockage. ${ }^{3}$ Mothers with a recurrent blocked duct were often advised to change their diet to one with more polyunsaturated fat or use a supplement, lecithin. ${ }^{3}$ A dietary source of lecithin is mainly soy or eggs. It would appear to be a good practice for lactating mothers in Chongqing to eat lots of eggs. However, in view of the possibility of egg allergy, Hong Kong mothers may be better advised to eat more soy products. Mothers in this study group appeared to eat very few soy products.

High milk production together with 
Both breasts were engorged. Left breast showed mild tenderness at 2 o'clock position, nipple slightly sore. Right breast showed a crack at base of nipple
Poor latch, sore nipple, cracks in nipple, and breast engorgement (a) Relief tenderness by milk expression in left breast (b) Treatment of the crack in right breast with local antibiotic

(c) Correction of the wrong position and latch that had caused the crack and inadequate emptying

(d) Advice on dietary change: her special diet that had encouraged too much milk production: fish soup, chicken soup, pork, egg, cow milk, etc should be changed to a more plant-based diet

Left breast tenderness and redness over 12-2 o'clock position

\section{Blocked duct}

Milk was expressed to clear the blocked duct. There was no more tenderness afterwards. Discharged with no medication. Mother was advised to feed regularly and not to over-stimulate by pump because blocked duct can easily occur if there is an overproduction of milk

\section{White bleb was removed by $25 \mathrm{G}$ needle, followed by milk expression to clear the blockage. All redness and tenderness subsided \\ Blocked duct}

\author{
Nipple and areola of both breasts \\ were swollen resulting from pumping, \\ tenderness at right breast at 11-12 \\ o'clock position, a tender white bleb \\ in the nipple \\ Left breast swelling with an area of \\ fluctuation

A follow-up phone call 2 days later confirmed that all pain had disappeared inadequate emptying definitely poses a problem. Many Hong Kong mothers took both Chinese remedies (herbs, fish soups) and drank western teas (eg fenugreek) to increase milk production. Nearly all breastfeeding mothers had a breast pump. Some mothers pumped milk more often to produce an excess for later use. Indeed quite a number of the studied mothers had plenty of stored milk in their refrigerator. Working mothers may have stopped pumping during weekends. Such irregular breast emptying may cause the problem of milk stasis. The presence of fatigue, stress, and an imbalanced diet can encourage inflammation that can easily progress to mastitis. Recurrence of blocked duct/mastitis may occur if the mother's diet and practice of feeding or pumping are not corrected.

A diet rich in white sugar or corn syrup, pastries, and cakes can enhance the growth of fungus but was generally not observed in our subjects. This may explain why fungal infection was rare. A natural well-balanced diet with whole grains, plenty of vegetables and fruits, and no excessive animal products should be recommended. Refined sugary foods, foods with chemicals, colouring agents, and preservatives should be avoided.

\section{Medical services}

A substantial number of nurses had passed the examination that qualified them as an International Lactation Consultant. They worked mainly in the maternity wards of hospitals and MCHCs in
Hong Kong. They were very successful in initiating breastfeeding. Some hospitals ran a breastfeeding clinic to support mothers after discharge from the maternity ward but they were not available round the clock. Most mothers with breastfeeding problems attended a MCHC to seek for help. Other mothers chose to see their family doctors. In general, doctors had little training in dealing with problems related to breastfeeding. In 2011, the Department of Health produced a self-learning kit on breastfeeding for any doctor who was interested, but it is difficult for the public to identify such doctors.

Breast pain can sometimes be unbearable. Some patients described it as worse than labour pain. It is unknown from this study how many mothers had stopped breastfeeding because of the pain or how many ended up in hospital with a high fever and abscess that required surgery. Many patients in this study stated that after earlier treatment failed, they had no idea where else to seek further help. Others hesitated to seek medical help because they were afraid they would be told to stop breastfeeding. The mothers in this study were perhaps exceptional. They had tried very hard to find a solution for their pain even though it might have taken a number of days. These mothers deserve a better medical service. The Secretary for Food and Health has stated that the government is very supportive of breastfeeding and is ready to collaborate with health care professional bodies or non-governmental organisations in training personnel and promoting breastfeeding. ${ }^{12}$ 
Setting up breastfeeding clinics is the correct approach. These clinics can be run by MCHCs or a Baby-Friendly Hospital and should be full time and open to all. Doctors and lactation consultants can accumulate clinical experience faster and can then act as professional trainers. There is also a need for more local research on the diet and health of lactating mothers, especially those in confinement, so that appropriate education can be delivered to doctors, lactation consultants, midwives, peer counsellors, confinement nannies, and the public.

This study was limited by its retrospective nature. There was a lack of standard protocols for data recording and retrieval. Not all women were followed up to determine if they had completely recovered since it is difficult to do so in a private clinic. What is certain is that those with engorgement and a blocked duct felt immediate relief the moment they left the clinic. It is also quite possible that many cases of breast pain were treated by other doctors and lactation consultants. The data of this study may thus not be representative of Hong Kong in general.

\section{Conclusion}

Blocked duct was the most common cause of breast pain in lactating mothers. Without prompt relief it may progress to mastitis/breast abscess or the mother may choose to stop breastfeeding. It may be a suitable time for Hong Kong to set up one or more public full-time breastfeeding clinics in order to provide a better service for lactating mothers and to facilitate professional training and research.

\section{Declaration}

The author has disclosed no conflicts of interest.

\section{References}

1. Baber FM. The current situation in Hong Kong. Hong
Kong Pract 1981;5:132-7.

2. Baby-Friendly Hospital Initiative Hong Kong Association. Available from: http://www.babyfriendly.org.hk/en/ breastfeeding-in-hk/breastfeeding-trend/. Accessed Feb 2016.

3. Lawrence RA, Lawrence RM. Breast feeding: a guide for the medical profession. 5th ed. St Louis: Mosby; 1999: 273-83.

4. Wilson-Clay B, Hoover K. The breastfeeding atlas. 5th ed. US: LactNews Press; 2013: 57-8.

5. Chan SM, Nelson EA, Leung SS, Cheng JC. Bone mineral density and calcium metabolism of Hong Kong Chinese postpartum women-a 1-y longitudinal study. Eur J Clin Nutr 2005;59:868-76.

6. Black AE, Wiles SJ, Paul AA. The nutrient intakes of pregnant and lactating mothers of good socio-economic status in Cambridge, UK: some implications for recommended daily allowances of minor nutrients. Br J Nutr 1986;56:59-72.

7. Takimoto $\mathrm{H}$, Yoshiike $\mathrm{N}$, Katagiri A, Ishida $\mathrm{H}$, Abe S. Nutritional status of pregnant and lactating women in Japan: a comparison with non-pregnant/non-lactating controls in the National Nutrition Survey. J Obstet Gynaecol Res 2003;29:96-103.

8. Leung SS, Woo J, Ho S, Lam TH, Janus ED. Hong Kong dietary survey. Aust J Nutr Diet 1988;55(Suppl):S11-4.

9. Morimoto Y, Beckford F, Cooney RV, Franke AA, Maskarinec G. Adherence to cancer prevention recommendations and antioxidant and inflammatory status in premenopausal women. Br J Nutr 2015;114:13443.

10. Turner-McGrievy GM, Wirth MD, Shivappa N, et al. Randomization to plant-based dietary approaches leads to larger short-term improvements in Dietary Inflammatory Index scores and macronutrient intake compared with diets that contain meat. Nutr Res 2015;35:97-106.

11. Chen ZY, Kwan KY, Tong KK, Ratnayake WM, Li HQ, Leung SS. Breast milk fatty acid composition: a comparative study between Hong Kong and Chongqing Chinese. Lipids 1997;32:1061-7.

12. Hong Kong Paediatric Society, Hong Kong Paediatric Foundation. Summit on Breastfeeding and Early Childhood Nutrition in the First 1000 Days 2015; Abstract: 18. 